\title{
ESTUDAR OS SINDICATOS, ENTENDER O BRASIL
}

\section{STUDY TRADE UNIONS, UNDERSTAND BRAZIL}

\section{Victor de Oliveira Rodrigues ${ }^{*}$}

VÉRAS DE OLIVEIRA, Roberto; BRIDI, Maria Aparecida; FERRAZ, Marcos. (ORG). 2014. O Sindicalismo na Era Lula: paradoxos, perspectivas e olhares. Belo Horizonte: Fino Traço (Coleção Trabalho \& Desigualdade).

Dizer que o Brasil não é para principiantes, frase atribuída a Tom Jobim e mencionada de passagem nos debates acadêmicos sobre o país, continua fazendo sentido. O sociólogo Francisco de Oliveira (2003), ao sintetizar os dilemas e impasses que caracterizam a formação socioeconômica brasileira, utilizou a feliz metáfora do ornitorrinco. O Brasil, assim como este animal natural da Austrália e da Tasmânia, seria uma esdrúxula mistura de fatores contraditórios. Nas terras tupiniquins, no entanto, o polo atrasado e o moderno, o mercado de trabalho formal e o informal, longe de serem antagônicos, se complementam e fazem com que o capitalismo se reproduza de forma desigual e combinada.

No início do século XXI, inúmeros economistas, politólogos e sociólogos se debruçaram para compreender a profundidade, as contradições, os impactos e o legado das mudanças ocorridas no Brasil com a eleição do ex-líder operário e fundador do Partido dos Trabalhadores (PT), Luiz Inácio Lula da Silva, que governou o país entre os anos 2002 e 2010. O lulismo, na definição de André Singer (2012), foi um reformismo fraco, ou seja, um arranjo social que, por um lado, aliou políticas sociais compensatórias e moderada redistribuição de renda para os segmentos sociais subalternos e, por outro, buscou manter intactos os privilégios e garantir a reprodução das riquezas da elite econômica do país. Em síntese, o lulismo buscou harmonizar, a partir da mediação do Estado, as demandas e reivindicações do mundo do trabalho com a agenda do capital.

Nesse sentido, é impossível compreender o Brasil atual sem analisar um dos polos constituintes do arranjo lulista: o mundo do trabalho e, sobretudo, as dinâmicas das lutas dos trabalhadores e seus sindicatos durante a chamada era Lula (2002-2010). É justamente esse o propósito do livro "O Sindicalismo na Era Lula: Paradoxos, Perspectivas e Olhares", coletânea de artigos organizada pelos pesquisadores Roberto Véras de Oliveira, Maria Aparecida Bridi e Marcos Ferraz.

\footnotetext{
* Bolsista CAPES, doutorando no Programa de Pós-graduação em Sociologia (PPGS) da Universidade Federal da Paraíba (UFPB) e membro do Laboratório de Estudos e Pesquisas em Políticas Públicas e Trabalho (LAEPT) da UFPB. E-mail: rodriguesvictorr@gmail.com
} 
O livro está dividido em duas partes e reúne doze artigos de pesquisadores das relações de trabalho e sindicais no Brasil. Na primeira parte, intitulada "Leituras e estratégias sindicais: entre a participação e o confronto", os artigos traçam um panorama geral da ação sindical com destaque para a atuação das centrais sindicais.

$\mathrm{O}$ primeiro artigo, $O$ sindicalismo na era Lula: entre paradoxos e novas perspectivas, assinado por Roberto Véras de Oliveira e Ângela Maria Carneiro Araújo, contrasta a atuação sindical nos anos 1990 e nos anos 2000, buscando destacar as novidades, os dilemas, as contradições e as possibilidades colocadas pelo novo cenário, marcado pela eleição do ex-líder sindicalista Luís Inácio Lula da Silva, cuja trajetória política confunde-se, em grande medida, com a própria trajetória do chamado sindicalismo-CUT. Os autores concluem que, diante da primeira experiência histórica de um governo encabeçado pelo PT, a CUT teve, em certa medida, uma parte da sua atuação comprometida.

A questão trabalhista e os desafios da ação sindical nos anos 2000 é o título do segundo artigo, realizado em coautoria por Mário Henrique Guedes Ladosky, José Ricardo Ramalho e Iram Jácome Rodrigues. Sem abrir mão de uma abordagem crítica e evitando a tentação dos reducionismos fáceis, os autores analisam atas e resoluções congressuais da CUT, entre os anos 2003-2013, e refutam a tese da passividade e a crítica de que esta tenha se tornado uma central sindical acomodada. Segundo os autores, ainda que as ações cutistas não tenham tido a mesma visibilidade que tiveram em outros momentos históricos, como, por exemplo, nos anos 1980, a CUT foi capaz de aproveitar as oportunidades oferecidas pela conjuntura, diversificando seu repertório de atuação, se posicionando estrategicamente em espaços tripartites para evitar retrocessos e garantir, paulatinamente, a aprovação de sua agenda.

Marcos Ferraz e Maria Aparecida Bridi aportaram o terceiro artigo da coletânea: Olhares sindicais sobre o governo Lula: a percepção dos dirigentes sindicais. Estes autores buscaram captar e analisar as expectativas e as avaliações de sindicalistas atuantes no estado do Paraná e vinculados a diferentes centrais sindicais, em relação aos governos Lula. Foram selecionados líderes sindicais representativos de um amplo espectro político e ideológico: a CUT, a Força Sindical e a CSP-Conlutas. Fazem, ainda, considerações de ordem metodológica, concluindo que não cabe ao cientista social dizer qual orientação sindical é mais correta, mas, sim, demonstrar e desvendar as perdas e conquistas que estão implicadas nas escolhas feitas pelos atores sociais: os trabalhadores e seus representantes.

A CSP-Conlutas em perspectiva é o quarto artigo. Andréia Galvão e Patrícia Trópia, analisam, a partir de dados produzidos nos congressos da entidade, a ainda curta trajetória da CSP-Conlutas. A entidade é fruto de uma dissidência da CUT por considerar que esta teria se transformado, sobretudo a partir da postura passiva diante da reforma da previdência, em 2003, ainda no primeiro governo Lula, numa central "governista" e adotado uma postura de subordinação aos governos "neoliberais" do PT. Diferentemente das demais sindicais nacionais, a CSP-Conlutas aglutina movimentos populares e movimentos sociais urbanos, como, por exemplo, movimentos estudantis. 
Sidartha Sória e Silva é o autor do quinto capítulo. As relações entre sindicalismo e fundos de pensão no governo Lula. O contexto marcado pela hegemonia do consenso de Washington - estruturado a partir do tripé financeirização, flexibilização e liberalização - implicou em profundas transformações no mundo do trabalho e ergueu novos obstáculos à ação sindical. Acuado, em postura defensiva, os sindicatos buscam responder aos desafios colocados pela avalanche neoliberal e adotam novas frentes de atuação. $\mathrm{O}$ autor analisa, criticamente, as relações entre o sindicalismo e os fundos de pensão no Brasil. A conjuntura política no governo Lula teria favorecido e estimulado a aproximação e a proliferação das iniciativas do sindicalismo CUT junto aos fundos de pensão.

O sexto texto é $O$ sindicalismo em questão em tempos de austeridade, do sociólogo português Hermes Augusto Costa. Ao tratar do caso europeu, o artigo destoa, em certa medida, dos textos precedentes. No entanto, escrevendo a partir de Portugal, situado na periferia da zona do euro, em um contexto marcado por políticas de austeridade desde a crise econômica de 2008, o autor busca traçar paralelos entre os desafios do sindicalismo europeu e do sindicalismo brasileiro na chamada era Lula. Em ambos os casos, os sindicatos estão desafiados a reforçar dois aspectos cruciais: por um lado, fortalecer as relações com as suas bases - cada vez mais heterogênea e diversificada - e, por outro, estreitar vínculos internacionais que os permitam enfrentar as corporações que atuam em escala global.

A segunda parte do livro se chama Ramos de atividade: transformações, conflitos e negociações. Nesta parte, o foco de análise é deslocado das centrais para os sindicatos. Trata-se de um panorama geral, lastreado em estudos de casos específicos, sobre a dinâmica sindical em alguns segmentos e categorias emblemáticas.

$\mathrm{O}$ artigo que abre a segunda etapa da coletânea é de José Dari Krein e Marilane Oliveira Teixeira: As controvérsias das negociações coletivas nos anos 2000 no Brasil. Os autores demonstram, a partir de uma análise pormenorizada, que houve significativos avanços em importantes indicadores do mercado de trabalho nos governos Lula. A recuperação do poder de compra do salário mínimo, garantida através de aumentos reais e sistemáticos acima da inflação, o aumento da formalização e a retração do mercado informal de trabalho são exemplos disso. No entanto, a geração de empregos em setores historicamente precários - tais como a construção civil e o telemarketing -, ainda que os sindicatos tenham aumentado seu poder de negociação, contribuiu para a não superação de traços estruturais do mercado de trabalho no Brasil, entre eles, a alta rotatividade e os baixos salários.

Leonilde Servolo de Medeiros, em O sindicalismo rural nas últimas décadas: mudanças e permanências, oitavo artigo da série, analisa as principais mudanças que têm afetado o sindicalismo rural desde o final dos anos 1980 e, sobretudo, a partir dos governos Lula. Segundo a autora, o sindicalismo rural tem tido que lidar com a aparição de movimentos sociais, com destaque para o Movimento dos Trabalhadores Sem Terra (MST), que também se colocam como representantes dos trabalhadores do campo. Como consequência disso, às tradicionais 
demandas dos sindicatos rurais - "acesso à terra, melhores salários e condições de trabalho" somam-se novas pautas: "crédito, assistência técnica, compras institucionais da produção etc" (MEDEIROS, 2014, p.247). Nos governos Lula essa dinâmica se reproduz e se intensifica, tendo como consequência, por um lado, o arrefecimento das reivindicações por reforma agrária e, por outro, o direcionamento, na zona rural, de políticas públicas para o apoio à agricultura familiar.

A atuação da Confederação Nacional dos Trabalhadores da Educação (CNTE), que representa os professores da educação básica, é analisada no nono artigo do livro: Sindicalismo docente no governo Lula: desafios de protagonismo e fragmentação, de Marcos Ferraz e Julián Gindin. Apesar de ser uma entidade de base municipal e estadual, a CNTE buscou aproveitar as possibilidades de diálogo abertas com os governos do PT e escolheu o governo federal como um dos seus principais interlocutores, tendo conseguido, por exemplo, a aprovação da lei do Piso Salarial Profissional Nacional. No entanto, se por um lado, a relação próxima e a afinidade política de parte considerável das lideranças do sindicalismo docente com os governos do PT facilitaram a implementação de pautas históricas da categoria, por outro, aprofundaram ainda mais o histórico processo de fragmentação, que tem sido um traço marcante do sindicalismo no setor.

O Sindicalismo telefônico do Rio de Janeiro na era Lula: orientações e práticas, de Marco Aurélio Santana e Paula Jatahy, é o décimo artigo. Os trabalhadores do setor das telecomunicações constituem uma das categorias mais afetadas pelos processos de privatização, flexibilização e terceirização que deram a tônica nos anos 1990 no Brasil. A substituição de trabalhadores estáveis por trabalhadores terceirizados e a diminuição das taxas de sindicalização corroeram o poder de ação do Sindicato. Ainda que fragilizado, o Sindicato busca diversificar sua pauta de reivindicações para atender o novo perfil dos trabalhadores do setor. Ainda que longe, no entanto, de repetir as ações de grande visibilidade dos anos 1980, o Sindicato soube aproveitar as possibilidades da era Lula para empreender a defesa dos trabalhadores.

O décimo primeiro artigo é As ambivalências das conquistas: os dilemas do Sindicato dos Bancários de São Paula na era Lula. Paulo Fontes e Francisco Macedo buscam questionar as análises que, talvez precipitadamente, concluíram que o Sindicato dos Bancários teria, durante os governos do PT, uma atuação marcada pela passividade, apatia e pelo governismo. Os autores evidenciam que, neste período, a atuação do Sindicato esteve marcada por um desafio equilibrista: por um lado, realizar a defesa de um governo que se mostrava aberto ao diálogo e, por outro, diversificar sua agenda de reivindicações para atender às expectativas de uma categoria profissional em constante mudança. Apesar de ser um dos sindicatos mais identificados com a trajetória da CUT e do PT, os autores avaliam que o Sindicato obteve "relativo sucesso" mesmo com as ambivalências que estavam postas.

O último artigo do livro é Quem somos, de que lugar falamos e por quais ideias nos mobilizamos: o perfil das lideranças do sindicato nacional dos docentes do ensino superior (ANDES$S N)$, de autoria de Patrícia Trópia, Darcilene Gomes, Sidartha Sória e Silva, Leonardo Barbosa e Silva e Edilson José Graciolli. O setor da educação de nível superior foi um dos principais 
alvos das políticas públicas durante os governos do PT. A partir de um survey realizado no $30^{\circ}$ Congresso do Andes, os autores apresentam um artigo descritivo sobre o perfil socioeconômico das lideranças sindicais, suas percepções sobre as condições de trabalho, suas motivações e suas preferências políticas e partidárias. No plano sindical e organizativo, a reforma da previdência, realizada pelo governo Lula em 2003 e, posteriormente, a expansão da rede oficial de ensino através do Reuni, desencadearam um processo de rupturas na base do Andes, fazendo com que este tenha novos concorrentes na busca pela representação dos docentes.

No último ano, o Brasil tem sido marcado por exorbitantes taxas de desemprego. Concomitantemente, tramitam, no Congresso Nacional e no Senado, tentativas de reformas trabalhistas e projetos de terceirização ${ }^{1}$ que visam precarizar ainda mais as relações de emprego e dificultar o acesso à aposentadoria, comprometendo, portanto, a qualidade de vida daqueles que dependem unicamente da sua força de trabalho para sobreviver.

Os sindicatos foram outrora diagnosticados como estando em franca decadência, ou seja, como tendo o seu poder de atuação inexoravelmente colapsados (Rodrigues, 1992). De uma perspectiva mais otimista, o sociólogo francês Michel Vakaloulis avalia que:

Esse ator mantém não apenas uma capacidade de perturbação anticapitalista, mas também a capacidade de reivindicação e de concretização de seus próprios objetivos, como mostra a relativa renovação sindical promovida ao longo do último período. Sabendo que estamos longe de assistir ao fim dos grandes movimentos reivindicativos do trabalho, convém então examinarmos atentamente as condições de possibilidade de sua realização" (VAKALOULIS, 2005, p.134).

A leitura de O Sindicalismo na Era Lula: Paradoxos, Perspectivas e Olhares, longe de esgotar o tema, ajuda a pensar justamente as "possibilidades de realização" da ação sindical. É uma obra de grande fôlego e bastante atual. Um dos pontos fortes do livro é a pluralidade de perspectivas e orientações teóricas, que se reflete nas diferentes abordagens e, também, na escolha dos objetos de análise. Trata-se de uma leitura indispensável não apenas para os estudiosos do sindicalismo, mas, sem dúvidas, para todos aqueles que desejam compreender aspectos centrais do Brasil contemporâneo. Serão os sindicatos brasileiros capazes de responder à altura os desafios colocados pelo atual momento histórico?

\section{Referências}

MEDEIROS, Leonilde Servolo de. O sindicalismo rural nas últimas décadas: mudanças e permanências. In: VÉRAS DE OLIVEIRA, Roberto; BRIDI, Maria Aparecida; FERRAZ, Marcos. (Org). O Sindicalismo na Era Lula: Paradoxos, Perspectivas e Olhares. Belo Horizonte: Fino Traço (Coleção Trabalho \& Desigualdade), 2014, p. 247-282.

1 O projeto de lei 4302, de 1998, que havia sido aprovado pelo Senado em 2002, foi desengavetado e aprovado na Câmara dos Deputados, em 22 de março de 2017. Sancionado pelo presidente Michel Temer em 31 de março de 2017, o PL 4302 transformou-se na lei ordinária 13429/2017 que, na prática, libera a terceirização das chamadas atividades-fim das empresas. 
OLIVEIRA, Francisco de. Crítica à razão dualista: O ornitorrinco. São Paulo: Boitempo, 2003.

RODRIGUES, Leôncio Martins. Destinos do Sindicalismo. São Paulo: Edusp, 1992.

SINGER, André. Os sentidos do Lulismo: reforma gradual e pacto conservador. São Paulo: Companhia das Letras, 2012.

VAKALOULIS, Michel. Antagonismo social e ação coletiva. In: LEHER; Roberto; SETÚBAL, Mariana (Org.). Pensamento crítico e movimentos sociais: diálogos para uma nova práxis. São Paulo: Cortez, 2005, p. 126-140. VÉRAS DE OLIVEIRA, Roberto; BRIDI, Maria Aparecida; FERRAZ, Marcos. (ORG). O sindicalismo na Era Lula: Paradoxos, Perspectivas e Olhares. Belo Horizonte: Fino Traço. (Coleção Trabalho \& Desigualdade), 2014.

Recebido em 24/07/2017 Aceito em 19/03/201 